\title{
The hepatoprotective activity of the herbal preparation Salivin against carbon tetrachloride (Ccl4) induced hepatotoxicity in rabbits
}

\author{
Daarimaa Khurelbat ${ }^{1 \star}$, Mandakhnaran PurevkhuU ${ }^{1}$,Batgerel Luvsansharav ${ }^{2}$, \\ Sarantsetseg Bandi ${ }^{2}$, Davaasuren Tseveen ${ }^{1}$, Tsetsegmaa SanjJav ${ }^{1}$, \\ Enkhjargal Dorjbal ${ }^{1}$, Ambaga Miegombo ${ }^{2}$
}

\footnotetext{
${ }^{1}$ School of Pharmacy and Biomedicine, Mongolian National University of Medical Sciences

${ }^{2}$ New Medicine" Medical Institute of Mongolia
}

\begin{tabular}{l}
\hline ARTICLE INFO \\
\hline Received 22 August 2014 \\
Accepted 12 September 2014 \\
\hline
\end{tabular}

\section{Keywords:}

salivin,

carbon tetrachloride,

hepatoprotective activity.

\begin{abstract}
Recently, a trend has developed towards employing certain herbal medicines to manage hepatotoxicity. The present study is that of an assessment of the efficacy of a herbal preparation of Salivin (HPS), a combination of the herbs of Saussurea amara (L.)DC., Salsola collina Pall., Achillea asiatica Serg. and rhizomes of Glycyrrhiza uralensis Fisch, in rabbit models, against CCl4-induced hepatic damage. In so doing, an extract of HPS $(200 \mathrm{mg} / \mathrm{kg}$ body weight/day), along with reference control tablets of Carsil (Silymarin 35 $\mathrm{mg})(250 \mathrm{mg} / \mathrm{kg}$ body weight/day) (which is known for its hepatoprotective effects) were administered, along with the standard diet.

The experimental group of rabbits received HPS orally for 28 days, which resulted in a decrease in blood enzymes (aspartate aminotransferase, alanine aminotransferase, alkaline phosphatase), compared to the control.

Evidenced by biochemical and histopathological studies, it is concluded that the polyherbal formulation HPS showed hepatoprotective activity against induced CCl4 hepatotoxicity in rabbits.
\end{abstract}

\section{INTRODUCTION}

Hepatotoxicity is the most widespread pathology worldwide, representing up to $83 \%$ of all cases. Hepatitis, viral infections, food additives, alcohol, toxic industrial chemicals, and air and water pollutants are the major risk factors of liver toxicity [11]. Chronic hepatic diseases stand as one of today's foremost health troubles, with liver cirrhosis and drug induced liver injury being the ninth leading cause of death in western and developing countries.

With regard to chronic hepatitis (brought about by the hepatitis $\mathrm{B}$ and $\mathrm{C}$ viruses), current statistics put forward that 350 million people are infected by the viruses. In particular, 170 million persons are $C$ virus carriers. Statistical data also show that, every year, chronic hepatitis kills one million people, and $70-90 \% \mathrm{C}$ virus carriers are exposed to liver cancer [23].

\section{Corresponding author}

e-mail: daariimaa@mnums.edu.mn
Herbs have been a huge source of natural substances used to treat and prevent several illnesses, among these, chronic hepatic diseases. Therefore, it is vital to identify the toxicity that might take place as a consequence of using certain herbal combinations [2]. Saussurea amara (L.)DC, Salsola collina Pall., and Achillea asiatica Serg., Glycyrrhiza uralensis Fisch. are all used in traditional Mongolian Medicine, and have been reported to protect or cure hepatobiliary disorders, as well as to bring about positive effects upon the metabolism, function and structure of the liver $[1,3,6,10,14-18,21]$. Hence, it is necessary to explore and develop such herbal medicines scientifically.

Carbon tetrachloride $\left(\mathrm{CCI}_{4}\right)$ has been widely used in animal models to investigate chemical toxin-induced liver damage. The most remarkable pathological characteristics of $\mathrm{CC}_{4}$-induced hepatotoxicity are fatty liver, cirrhosis and necrosis. These effects have been thought to result from the formation of reactive intermediates such as trichloromeyhyl free radicals $\left(\mathrm{CCI}_{3}^{+}\right)$that have been metabolized by 
the mixed function cytochrome $\mathrm{p}-450$ in the endoplasmic reticulum [13].

Silymarin is a standardized hepatoprotective extract of Silybum marianum (Compositae) that reverses hepatotoxininduced alterations of biochemical parameters. It has been, for a long time, the most thoroughly investigated of all the hepatoprotective medicinal plants in preventing liver damage induced by carbontetrechloride, D-GalN and paracetamol in rat models [9]. Silymarin has been employed as a standard for comparison in our study.

\section{METHODS}

\section{Animals}

Our experiment was performed using 32 Chinchilla rabbits with initial weights of $1.5-2.5 \mathrm{~kg}$. The animals were kept under standard vivarium conditions, with the same care and feeding, light and temperature regime, and with free access to water. The experimental protocol for the present study was approved by the Institutional Animal Ethical Committee (IAEC) of the National University Medical Sciences of Mongolia.

\section{Chemicals}

The chemical used for inducing hepatic injury, carbon tetrachloride $\left(\mathrm{CCl}_{4}\right)$ (Sigma Chemicals, USA), was diluted in liquid paraffin at a 1:2 ratio, and administered subcutaneously at a dose of $2 \mathrm{ml} / \mathrm{kg}$ body weight.

\section{Preparation of extract}

In this work, $10 \mathrm{~g}$ of the powdered Herbal preparation, Salivin, was extracted by way of $100 \mathrm{ml} 70 \%$ ethanol, and the ethanol was then removed under vacuum. The solution was subsequently diluted with distilled water.

\section{Study design}

Rabbits of body weight $1.5-2.5 \mathrm{~kg}$ were selected. The total study population of thirty-two (32) rabbits was placed within four (4) groups, eight (8) animals each. The different groups were treated as follows:

- Group I: Normal (intact),

- Group II: Control (induction of $\mathrm{CCI}_{4}$ without using any drugs),

- Group III: CCI + Salivin (200 mg/kg b. w.,p. o.),

- Group IV: $\mathrm{CCI}_{4}+$ Silymarin (250 mg/kg b. w.,p. o.). The animals that were treated with extracts of HPS and Carsil (Silymarin $35 \mathrm{mg}$ ) had this done on a daily basis for 28 days. The serum was subjected to diverse biochemical tests, and alanine aminotransferase (ALT), aspartate aminotransferase (AST), alkaline phosphatase (ALP), levels were determined using an automated analyzer "Humylazer 2000" (Human, Germany) at Khuljborjigon Hospital, Ulaanbaatar, Mongolia. The statistical analysis was performed using SPSS (16 version). The critical significance level when testing the statistical hypotheses is $\mathrm{p}<0.05$

\section{Histopathology}

The extracted liver tissues, which were previously trimmed into $2 \mathrm{~mm}$ thicknesses, were fixed with buffered formaldehyde for $24 \mathrm{~h}$. The fixed tissues were then processed, including being embedded in paraffin, then being sectioned and rehydrated. The histological examination by the above-mentioned conventional methods was evaluated by way of the index of $\mathrm{CCI}_{4}$-induced necrosis, through assessing the morphological changes in the hematoxylin and eosin (H\&E).

\section{RESULTS}

The levels of AST, ALT and ALP shown in Table 1. Our results reveal that serum AST significantly increased $(p<0.018)$ in the induced liver damage within the animals groups II, III and IV, in comparison to normal control. When comparing animals treated with extract of HPS, with experimental animals, on the $7^{\text {th }}$ day of drug administration, the level of serum AST decreased by $43 \%(\mathrm{p}<0.05)$; on the $14^{\text {th }}$ day, by $42,8 \%(\mathrm{p}<0.04)$; on the 28 th day, by $46.7 \%$ $(\mathrm{p}<0.01)$. Hence, serum AST significantly decreased after treatment with HPS $(p<0.05)$, with respect to the control group. Moreover, HPS $(200 \mathrm{mg} / \mathrm{kg})$ significantly $(\mathrm{p}<0.05)$ reduced serum ALT in carbon tetrachloride $(\mathrm{CCl} 4)$-induced liver injuries in rabbits by $16.3-93.3 \%$ (Table 1 ).

Table 1 shows that the serum ALP significantly increased $(\mathrm{p}<0.01)$ in liver damage in the groups II, III and IV, in comparison to normal control. When comparing animals treated with extract of the HPS with the experimental animals, on the $7^{\text {th }}$ day, the level of serum ALP decreased by $28.3 \%(\mathrm{p}<0.02)$; on the $14^{\text {th }}$ day, by $38,7 \%(\mathrm{p}<0.05)$; on the 28 th day, by $46.2 \%(\mathrm{p}<0.01)$. Thus, serum ALP significantly decreased after treatment with HPS $(\mathrm{p}<0.05)$, with respect to the control group.

Table 1. Effect of HPS on serum AST, ALT and ALP level in hepatotoxic rabbits

\begin{tabular}{|c|c|c|c|c|c|}
\hline \multirow{2}{*}{ 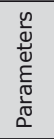 } & \multirow{2}{*}{ 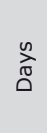 } & \multicolumn{4}{|c|}{ Groups } \\
\hline & & $\begin{array}{l}\text { Normal } \\
(n=8)\end{array}$ & $\begin{array}{l}\text { Control } \\
(n=8)\end{array}$ & $\begin{array}{l}\text { "Salivin" } \\
(n=8)\end{array}$ & $\begin{array}{c}\text { "Silymarin" } \\
(\mathrm{n}=8)\end{array}$ \\
\hline \multirow{4}{*}{$\begin{array}{l}\text { AST } \\
(\mathrm{u} / \mathrm{I})\end{array}$} & 3 & \multirow{4}{*}{$39.7 \pm 2.1$} & $285.7 \pm 10.97 *$ & $207.4 \pm 8.88^{*}$ & $203.7 \pm 8.3^{*}$ \\
\hline & 7 & & $203.2 \pm 17.48^{* *}$ & $115.5 \pm 5.9 * *$ & $112.5 \pm 6.49 * *$ \\
\hline & 14 & & $120.2 \pm 10.85$ & $68.7 \pm 3.29$ & $80.8 \pm 5.17^{* *}$ \\
\hline & 28 & & $110.4 \pm 4.31 *$ & $58.8 \pm 3.7 *$ & $70.7 \pm 5.77 *$ \\
\hline \multirow{4}{*}{$\begin{array}{l}\text { ALT } \\
(\mathrm{u} / \mathrm{I})\end{array}$} & 3 & \multirow{4}{*}{$40.7 \pm 4.53$} & $347.1 \pm 10.14 *$ & $290.2 \pm 19.03 *$ & $278.6 \pm 14.69 * *$ \\
\hline & 7 & & $256.3 \pm 16.76$ & $195.8 \pm 7.85$ & $239.9 \pm 19.12 *$ \\
\hline & 14 & & $118.5 \pm 5.91 *$ & $74.3 \pm 1.22 *$ & $98.05 \pm 3.10$ \\
\hline & 28 & & $124.8 \pm 6.36 *$ & $64.5 \pm 4.39 * *$ & $71.16 \pm 4.02 *$ \\
\hline \multirow{4}{*}{$\begin{array}{l}\text { ALP } \\
(\mathrm{u} / \mathrm{I})\end{array}$} & 3 & \multirow{4}{*}{$128.39+6.31$} & $288.2 \pm 7.22 *$ & $234.75 \pm 9.78 *$ & $247.71 \pm 10.15$ \\
\hline & 7 & & $273.04 \pm 3.41$ & $195.93 \pm 8.98$ & $212.0 \pm 6.29 * *$ \\
\hline & 14 & & $279.46 \pm 3.79 * *$ & $171.15 \pm 15.39 *$ & $180.86 \pm 8.8$ \\
\hline & 28 & & $266.56 \pm 8.20 *$ & $143.46 \pm 3.56^{* *}$ & $138.44 \pm 9.52 *$ \\
\hline
\end{tabular}

AST: Aspartate aminotransferase,

ALT: Alanine aminotransferase,

ALP: Alkaline phosphatase.

Notes:

* statistically significant difference, as compared to control at $\mathrm{p}<0.05$.

$* *$ - the difference is statistically significant, compared with control at $\mathrm{p}<0.001$.

The increased fatty degeneration, cytoplasmic vacuolization and necrosis provided histopathological evidence of 
tissue injury in the CCl4-treated group (Figure 1). However, these histopathologic indexes were significantly improved by the administration of HPS and Silymarin (Figure 1).

In the control group, normal hepatic cells are characterized by having well-defined cell linings, a prominent nucleus and a prominent central vein surrounded by reticular fibers (Figure 1(A)). However, massive necrosis formation, hepatocytes ballooning, distortion of the hepatocytes, shrinkage of nucleus, clear cell foci formation, loss of cellular boundaries, and reticular fibers were observed in CCl4-intoxicated rats liver section. Thus, this is indicative of extensive liver injuries (Figure 1(B)). Pretreatment of HPS at $200 \mathrm{mg} / \mathrm{kg}$ partly provided hepatoprotective activity.
The histopathological changes, such as necrosis, ballooning, clear cell foci formation, and structural loss of hepatic lobules, are not as evident, and the histological architecture of liver sections of the rabbits treated with HPS at $200 \mathrm{mg} / \mathrm{kg}$ showed almost normal lobular pattern, with a mild degree of necrosis, ballooning, clear cell foci and visible reticular fibers around the central vein. This is almost comparable to the control and to the Silymarin treated group (Figures 1(C), and 1(D). We propose that certain herbal components (flavonoids, triterpene, saponins and glyccyrrhizic acid), in combination with other components present in the HPS, are responsible for the reduction of hepatotoxicity in the treatment groups.
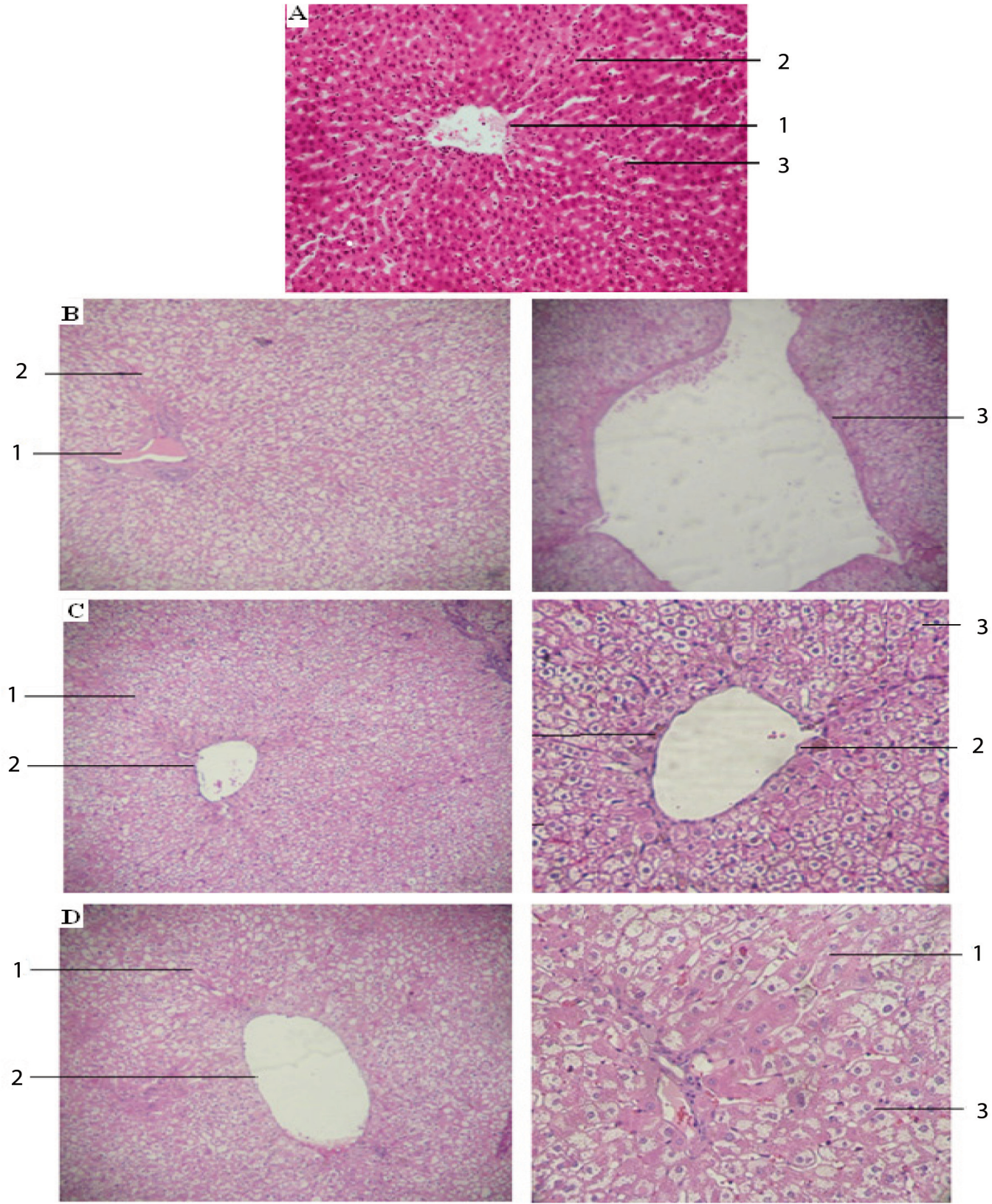

Figure 1. Effects of HPS on histopathology studies in CCl4-induced hepatotoxicity in rabbits. Typical images were chosen from the different experimental groups (original magnification $200 \times$ )

A. Normal group; central vein (1), plates of hepatocytes (2), hepatocytes (3);

B. Control group; hematoma of central vein (1), distortion of hepatocytes (2), and broad infiltration of the lymphocytes and Kupffer cells around the central vein, as well as the loss of cellular boundaries (3);

C. CCl4 and HPS (200 mg/kg)-treated group; plates of hepatocytes (1), central vein (2), binucleate hepatocytes (3);

D. CCl4 and Silymarin (225 mg/kg)-treated group; plates of hepatocytes (1), central vein (2), binucleate hepatocytes (3). 


\section{DISCUSSION}

Referring to the data of Glasl et.al. $[3,1]$, the dose dependent, bile enhancing effect of the crude water extract suggests a synergistic effect of cynaripicrin and flavonoids in the applied multi-component mixtures containing Saussurea $\operatorname{amara}($ L.)DC.

The herb Salsola collina Pall. also contains a variety of amino acids, flavonoids, glycosides and vitamins. Moreover, it has a known positive effect on the metabolism of fats, and on the liver. In addition, it is known to regulate cholesterol and sugar in the blood, and it is recommended for weight reduction $[5,8,15,17,18,20,21]$.

The herb Achillea L. (Compositae or Asteraceae) is a widely distributed medicinal plant throughout the world and has been used since ancient times. Several effects, such as that of being anti-inflammatory, antibacterial, antihypertensive, as well as anti-hyperlipidemia and anti-tumor, have been reported for Achillea. Of note, it is widely used in traditional medicine for gastrointestinal disorders, and there are some scientific reports of its effects, such as it being antispasmodic, choleretic, antiulcer, antibacterial (Helicobacter pylori) and hepatoprotective on the gastrointestinal tract [7].

Glycyrrizin is the major bioactive triterpene glycoside of licorice root (Glycyrrhiza Radix) extracts. This possesses a wide range of known pharmacological properties (anti-inflammatory, anti-ulcer, anti-allergic, anti-dote, antioxidant, anti-tumor, anti-viral etc.). Furthermore, Glycyrrhizin, which we isolated from Glycyrrhiza uralensis, has a hepatoprotective activity $[12,16,19,22]$.

Our hypothesis, that HPS possesses a hepatoprotective effect, was based on the information contained in the above, and this is confirmed our findings. Usually, the extent of hepatic damage is assessed by the increased level of cytoplasmic enzymes (ALT, AST and ALP), thus, this leads to a leakage of large quantities of enzymes into the blood circulation. This is normally associated with massive centrilobular necrosis, ballooning degeneration and cellular infiltration of the liver [4]. Our findings are that an extract of the HPS, when administered, exhibited a decrease in serums AST, ALT and ALP.

Therefore, our studies indicate that an extract of HPS has a hepatoprotective effect in experimental rabbits.

\section{ACKNOWLEDGMENTS}

This study was supported by a grant (SSA_036/2012) from the Mongolian Foundation for Science and Technology, Ministry of Education and Science, Mongolia (2012-2014).

\section{REFERENCES}

1. Daariimaa Kh. The phytochemical study of Saussurea amara (L.) DC. Ph.D dissertation, 2006; Ulaanbaatar.
2. Feroz Z, Khan RA, Amber, Mahayrookh. Hepatoprotective effect of a herbal drug on CCl4 induced liver damage. Pak J Pharm Sci. 2013 Jan; 26 (1): 99-103.

3. Glasl S, et al. Choleretic effects of the Mongolian medicinal plant Saussurea amara (L.) in the isolated perfused rat liver. J.Planta Med. 2007; 73 (1): 59-66.

4. Gowri ShNL. Manavalan R, Venkapaya D, David Raj. Hepatoprotective and antioxidant effects of Commiphora berryi (Arn) Engl bark extract against CCl4-induced oxidative damage in rats. Food Chem Toxicol. 2008; 46 (9): 3182-3185.

5. Houari S, Naboka OI, Glushchenko AV. Influence of extractions of Ruta, Artichoke, Bupleurum and Salsola collina upon the indexes of peroxidation of rats lipids, on against a background of CCL4 action: actual questions of development of new drugs. Book of abstracts of XX international scientific and practical conference of young scientists and students, devoted to the $90^{\text {th }}$ anniversary of Doctor of Science in pharmacy, Professor Dmitri Pavlovych Salo, 2013: 25-26.

6. Ligaa U. Medicinal plants of Mongolia used in Mongolian traditional medicine. Korea: KCA Press; 1996: 333-334.

7. Niazmand S, Khooshnood E, Derakhshan M. Effects of Achillea wilhelmsii on rat gastric acid output, at basal, vagotomized, and vagal-stimulated conditions. Phcog Mag. 2010; 6: 282-285.

8. Nikiforov S B, Semenov AA, Syrchina AI. Effect of the aqueous extract of the aboveground parts of Salsola collina Pall on the distribution of cholesterol in blood serum lipoprotein fractions, in rabbits with experimental cholelithiasis. Khimiko-Farmatsevticheskii Zhurnal. 2012; 36 (10): 27-28.

9. Palanisamy D, Syamala, Kannan E, Bhojraj S. Protective and therapeutic effects of the Indian medicinal plant Pterocarpus santalinus, on D-galactosamine-induced liver damage. Asian Journal of Traditional Medicine. 2007; 2: 51-57.

10. Pitschmann A, et al. Traditional Mongolian Medicine history and status quo. Phytochemistry Reviews. 2013; 12(4): 943-959.

11. Rahmat A Khan, et al. Hepatoprotective activity of Sonchus asper against carbon tetrachloride-induced injuries in male rats. $B M C$ Complement Altern Med. 2012; 12: 90.

12. Recknagel RO. Carbon tetrachloride hepatotoxicity. Pharmacol Rev, 1967; 19: 145-195.

13. Recknagel RO, Glende EA, Dolak JA, Waller RL. Mechanism of carbon tetrachloride toxicity. Pharmacol Ther. 1989; 43: 139-154.

14. Saeidnia S, Gohari AR, Kiuchi F. A review on the phytochemistry and medicinal properties of the genus Achillea. Daru. 2011;19 (3): 173-186.

15. Saratikov AS, et al. Hepatoprotective properties of a lokhein extract from Salsola collina Pall. Rastitel nye Resursy. 2004; 40 (2): 133-138.

16. Shim SB, Kim NJ, Kim DH. Beta-glucuronidase inhibitory activity and hepatoprotective effect of 18 beta-glycyrrhetinic acid, from the rhizomes of Glycyrrhiza uralensis. Planta Med. 2000; 66: 40-43.

17. Tseden $\mathrm{P}$. The pharmacological study of Salsola collina Pall. Ph.D dissertation, 1998; Ulaanbaatar.

18. Vengerovskii AI, Chucholin VS, Sadykh LM. Hepatoprotective properties of an extract from the above ground part of Salsola collina Pall. J.Rastitel Nye Resursy. 1989; 25 (4): 575-580.

19. Wang W, et al. Glycyrrhizic acid nanoparticles inhibit LPS-induced inflammatory mediators in 264.7 mouse macrophages, compared with unprocessed glycyrrhizic acid. International Journal of Nanomedicine. 2013; 8: 1377-1383.

20. Xiang Y, et al. A new alkaloid from Salsola collina. Yao Xue Xue Bao. 2007; 42 (6): 618-620.

21. Zhao YX, Ding XB. Studies on the alkaloids from Salsola collina Pall. Yao Xue Xue Bao. 2004; 39 (8): 598-600.

22. Zhang Q. Chemical analysis of the Chinese herbal medicine Gan-Cao (licorice). J Chromatogr. 2009; 13; 1216 (11): 1954-1969.

23. Zidan A, Scheuerlein H, Schule S. Epidemiological pattern of hepatitis B and C as etiological agents for hepatocellular carcinoma in Iran and worldwide. Hepat Mon., 2012; 12 (10): 684-688. 